Pacific Journal of Mathematics

LIMITS FOR MARTINGALE-LIKE SEQUENCES 


\section{LIMITS FOR MARTINGALE-LIKE SEQUENCES}

\section{ANTHONY G. MUCCI}

The concept of a martingale is generalized in two ways. The first generalization is shown to be equivalent to convergence in probability under certain uniform integrability restrictions. The second generalization yields a martingale convergence theorem.

1. Introduction. In what follows $\left\{X_{n}, \mathfrak{V}_{n}\right\}$ is a sequence of integrable random variables and sub-sigma fields on the probability space $(\Omega, \mathfrak{B}, P)$ such that

$$
\begin{aligned}
& X_{n} \text { is } \mathfrak{B}_{n} \text {-measurable } \\
& \mathfrak{V}_{n} \subset \mathfrak{B}_{n+1} \\
& \mathfrak{B}=\sigma\left(\bigcup_{1}^{\infty} \mathfrak{B}_{n}\right) .
\end{aligned}
$$

We call the sequence $\left\{X_{n}, \mathfrak{B}_{n}\right\}$ an adapted sequence. In [2] Blake defines $\left\{X_{n}, \mathfrak{B}_{n}\right\}$ as a game which becomes fairer with time provided

$$
E\left(X_{n} \mid \mathfrak{B}_{m}\right)-X_{m} \stackrel{P}{\longrightarrow} 0 \text { as } n \geqq m \longrightarrow \infty,
$$

i.e., provided, for all $\varepsilon>0$ :

$$
\lim _{n>m} P\left(\left|E\left(X_{n} \mid \mathfrak{B}_{m}\right)-X_{m}\right|>\varepsilon\right)=0 \text { as } m \longrightarrow \infty \text {. }
$$

It is proven in [1] that if $\left\{X_{n}, \mathfrak{B}_{n}\right\}$ becomes fairer with time, and if there exists $Z \in L_{1}$ with $\left|X_{n}\right| \leqq Z$ for all $n$, then $X_{n} \stackrel{\mathscr{L}_{1}}{\longrightarrow} X$, some $X \in \mathscr{L}_{1}$.

In the present paper we will show that $X_{n} \stackrel{s_{1}}{\longrightarrow} X$ under the less restrictive assumption that $\left\{X_{n}\right\}$ is uniformly integrable. We will further show that in the presence of uniform integrability $\left\{X_{n}, \mathfrak{B}_{n}\right\}$ becomes fairer with time if and only if $\left\{X_{n}\right\}$ converges in probability, i.e.,

$$
E\left(X_{n} \mid \mathfrak{B}_{m}\right)-X_{m} \stackrel{P}{\longrightarrow} 0 \Longleftrightarrow X_{n}-X_{m} \stackrel{P}{\longrightarrow} 0 .
$$

Finally, by using the more restrictive concept that $\left\{X_{n}, \mathfrak{B}_{n}\right\}$ is a martingale in the limit, namely,

$$
\lim _{n \geq m \rightarrow \infty}\left(E\left(X_{n} \mid \mathfrak{B}_{m}\right)-X_{m}\right)=0 \text { a.e., }
$$

we will prove (Theorem (2)) a generalization of a standard martingale convergence theorem. 
2. Proposition 1. Let the sequence $\left\{X_{n}\right\}$ be uniformly integrable and assume

$$
\lim _{n \rightarrow \infty} \int_{A} X_{n} \text { exists, all } A \in \bigcup_{1}^{\infty} \mathfrak{B}_{n} .
$$

Then there exists $X \in \mathscr{L}_{1}$ such that

$$
\lim _{n \rightarrow \infty} \int_{A} X_{n}=\int_{A} X, \quad \text { all } \quad A \in \mathfrak{B} .
$$

Proof. Let $A \in \mathfrak{B}, \delta>0$. There exists $A_{0} \in \bigcup_{1}^{\infty} \mathfrak{B}_{n}$ with $P\left(A \Delta A_{0}\right) \leqq$ $\delta$. This, together with the augument in Neveu [3] (page 117) proves the desired result.

Remarks. Let $\Omega=[0,1)$ with Lebesgue measure. Let $\mathfrak{B}_{n}$ be the $\sigma$-field generated by the subintervals $A_{k, n} \equiv\left[k / 2^{n},(k+1) / 2^{n}\right), k=$ $0,1, \cdots, 2^{n}-1$. Set $X_{n}=\sum_{k=0}^{2^{n}-1}(-1)^{k} I_{A_{k}, n}$ where $I_{A}$ is the indicator function of $A$. Then for any $A \in \cup \mathfrak{B}_{n}$ we have $\lim _{n \rightarrow \infty} \int_{A} X_{n}=0$. Further, $\left\{X_{n}\right\}$ is uniformly integrable. However, $\left\{X_{n}\right\}$ does not converge in the $\mathscr{L}_{1}$-norm.

Proposition 2. Let $\left\{X_{n}\right\}$ be uniformly integrable and assume $\left\{X_{n}\right\}$ becomes fairer with time:

$$
\lim _{n \geqq m \rightarrow \infty} P\left(\left|E\left(X_{n} \mid \mathfrak{B}_{m}\right)-X_{m}\right|>\varepsilon\right)=0 .
$$

Then there exists $X \in \mathscr{L}_{1}$ such that $X_{n} \stackrel{\mathscr{S}_{1}}{\longrightarrow} X$.

Proof. Let $A \in \mathfrak{B}_{m}, p \geqq q \geqq m$. Then

$$
\begin{aligned}
\left|\int_{A} X_{p}-\int_{A} X_{q}\right| & =\left|\int_{A} E\left(X_{p} \mid \mathfrak{B}_{q}\right)-X_{q}\right| \\
& \leqq \int_{A\left(\left|E\left(X_{p} \mid \mathfrak{B}_{q}\right)-X_{q}\right|>\varepsilon\right)}\left|E\left(X_{p} \mid \mathfrak{B}_{q}\right)-X_{q}\right|+\varepsilon \\
& \leqq 2 \sup _{k} \int_{A\left(\left|E\left(X_{p} \mid \mathfrak{B}_{q}\right)-X_{q}\right|>\varepsilon\right)}\left|X_{k}\right|+\varepsilon .
\end{aligned}
$$

By uniform integrability and the assumption $\left(^{*}\right)$ we see that

$$
\lim _{n \rightarrow \infty} \int_{A} X_{n} \text { converges, all } A \in \bigcup_{1}^{\infty} \mathfrak{B}_{n} \text {. }
$$

By Proposition 1, there exists $X \in \mathscr{L}_{1}$ with

$$
\lim _{n \rightarrow \infty} \int_{A} X_{n}=\int_{A} X, \text { all } A \in \mathfrak{B} .
$$


Note that $\left\{E\left(X \mid \mathfrak{B}_{n}\right), \mathfrak{B}_{n}\right\}$ is a martingale and $E\left(X \mid \mathfrak{B}_{n}\right) \rightarrow X$ both in the $\mathscr{L}_{1}$ and the almost sure sense (Levy's Theorem). Since

$$
\int\left|X_{n}-X\right| \leqq \int\left|X_{n}-E\left(X \mid \mathfrak{B}_{n}\right)\right|+\int\left|E\left(X \mid \mathfrak{B}_{n}\right)-X\right|,
$$

it will be enough to show $\int\left|X_{n}-E\left(X \mid \mathfrak{B}_{n}\right)\right| \rightarrow 0$. Now

$$
\begin{aligned}
\int\left|X_{n}-E\left(X \mid \mathfrak{B}_{n}\right)\right|= & \int_{\left(X_{n} \geqq E\left(X \mid \mathfrak{B}_{n}\right)\right)}\left(X_{n}-E\left(X \mid \mathfrak{B}_{n}\right)\right) \\
& +\int_{\left(X_{n}<E\left(X \mid \mathfrak{B}_{n}\right)\right)}\left(E\left(X \mid \mathfrak{B}_{n}\right)-X_{n}\right) .
\end{aligned}
$$

Letting $n^{\prime} \geqq n$ and setting $A=\left(\left|E\left(X_{n}, \mid \mathfrak{B}_{n}\right)-X_{n}\right|>\varepsilon\right)$, we have

$$
\begin{aligned}
\int_{\left(X_{n} \geqq E\left(X \mid \mathfrak{B}_{n}\right)\right)}\left(X_{n}-E\left(X \mid \mathfrak{B}_{n}\right)\right) \leqq & \int_{A}\left|X_{n}\right|+\int_{A}\left|X_{n^{\prime}}\right| \\
& +\left|\int_{\left(X_{n} \geqq E\left(X_{n} \mid \mathfrak{B}_{n}\right)\right)}\left(X_{n^{\prime}}-X\right)\right|+\varepsilon \\
\leqq & 2 \sup _{k} \int_{A}\left|X_{k}\right| \\
& +\left|\int_{\left(X_{n} \geqq E\left(X \mid \mathfrak{B}_{n}\right)\right.}\left(X_{n^{\prime}}-X\right)\right|+\varepsilon .
\end{aligned}
$$

By uniform integrability and condition $\left(^{*}\right)$, the first integral is small. Letting $n^{\prime} \rightarrow \infty$, the difference in the remaining integral tends to zero. An identical analysis shows

$$
\int_{\left(X_{n}<E(X \mid \mathfrak{B})\right)}\left(E\left(X \mid \mathfrak{B}_{n}\right)-X_{n}\right) \longrightarrow 0
$$

REMARKS. Suppose $X_{n} \stackrel{\mathscr{L}_{1}}{\longrightarrow} X$. Then since

$$
\int_{A}\left|X_{n}\right| \leqq \int\left|X_{n}-X\right|+\int_{A}|X|
$$

we see that $\left\{X_{n}\right\}$ is uniformly integrable. Further

$$
\begin{aligned}
P\left(\left|E\left(X_{n} \mid \mathfrak{B}_{m}\right)-X_{m}\right|>\varepsilon\right) & \leqq \frac{1}{\varepsilon} \int\left|E\left(X_{n} \mid \mathfrak{B}_{m}\right)-X_{m}\right| \\
& \leqq \frac{1}{\varepsilon} \int\left|X_{n}-X_{m}\right|
\end{aligned}
$$

so $\left\{X_{n}, \mathfrak{B}_{n}\right\}$ becomes fairer with time. It is shown (Neveu [3], page 52):

$\left\{X_{n}\right\}$ is Cauchy in the $\mathscr{L}_{1}$ norm $\Longleftrightarrow\left\{X_{n}\right\}$ is uniformly integrable and $\left\{X_{n}\right\}$ is Cauchy in probability.

We tie these results together with Proposition 2 to get 
Theorem 1. Let $\left\{X_{n}, \mathfrak{B}_{n}\right\}$ be an adapted sequence. Then the following three statements are equivalent:

(a) There exists $X \in \mathscr{L}_{1}$ and $X_{n} \stackrel{\mathscr{1}_{1}}{\longrightarrow} X$.

(b) $\left\{X_{n}\right\}$ is uniformly integrable and $E\left(X_{n} \mid \mathfrak{B}_{m}\right)-X_{m} \stackrel{P}{\longrightarrow} 0$.

(c) $\left\{X_{n}\right\}$ is uniformly integrable and $X_{n}-X_{m} \stackrel{P}{\longrightarrow} 0$.

COROLlaRY 1. Let the adapted sequence $\left\{X_{n}, \mathfrak{B}_{n}\right\}$ be uniformly integrable. Then

$$
E\left(X_{n} \mid \mathfrak{B}_{m}\right)-X_{m} \stackrel{p}{\longrightarrow} 0 \Longleftrightarrow X_{n}-X_{m} \stackrel{p}{\longrightarrow} 0 .
$$

REMARKS. In the absence of uniform integrability we have neither implication. Consider the following two examples:

(1) Set $X_{n}=\sum_{1}^{n} y_{k}$ where $\left\{y_{k}\right\}$ is a sequence of independent identically distributed random variables with zero means. Set $\mathfrak{B}_{n}=$ $\sigma\left(y_{1}, y_{2}, \cdots, y_{n}\right)$. Clearly $\left\{X_{n}, \mathfrak{B}_{n}\right\}$ is a martingale, so $E\left(X_{n} \mid \mathfrak{B}_{m}\right)$ $X_{m} \stackrel{P}{\longrightarrow} 0$. But, if, for instance

$$
y_{k}=\left\{\begin{array}{rl}
1 & \text { with probability } \frac{1}{2} \\
-1 & \text { with probability } \frac{1}{2}
\end{array},\right.
$$

then

$$
\begin{aligned}
P\left(\left|X_{n}-X_{m}\right| \geqq 1\right) & =P\left(\left|\sum_{1}^{n-m} y_{k}\right| \geqq 1\right) \\
& =1-P\left(\sum_{1}^{n-m} y_{k}=0\right) \sim 1-\frac{c}{\sqrt{n-m}} \nrightarrow 0,
\end{aligned}
$$

so $X_{n}-X_{m} \stackrel{P}{\leftrightarrow} 0$.

(2) Let $\left\{y_{k}\right\}$ independent where $P\left(y_{k}=k^{2}\right)=1 / k^{2}$ and $P\left(y_{k}=0\right)=$ $1-1 / k^{2}$.

Then, setting $X_{n}=\sum_{1}^{n} y_{k}$ we have

$$
\left|E\left(X_{n} \mid \mathfrak{B}_{m}\right)-X_{m}\right|=E \sum_{m+1}^{n} y_{k} \geqq 1
$$

while

$$
\begin{aligned}
P\left(\left|X_{n}-X_{m}\right| \geqq \varepsilon\right) & =P\left(\sum_{m+1}^{n} y_{k} \geqq \varepsilon\right)=P\left(\bigcup_{m+1}^{n}\left(y_{k} \geqq \varepsilon\right)\right) \\
& \leqq \sum_{m+1}^{n} P\left(y_{k} \geqq \varepsilon\right)=\sum_{m+1}^{n} \frac{1}{k^{2}} \longrightarrow 0,
\end{aligned}
$$

so in this case $X_{n}-X_{m} \stackrel{p}{\longrightarrow} 0$ while $E\left(X_{n} \mid \mathfrak{B}_{m}\right)-X_{m} \stackrel{p}{\leftrightarrow} 0$. 
Recall now the definition that $\left\{X_{n}, \mathfrak{S}_{n}\right\}$ be a martingale in the limit, namely:

$$
E\left(X_{n} \mid \mathfrak{B}_{m}\right)-X_{m} \longrightarrow 0 \text { almost everywhere. }
$$

THEOREM 2. Let the adapted sequence $\left\{X_{n}, \mathfrak{B}_{n}\right\}$ be uniformly integrable and a martingale in the limit. Then there exists $X \in \mathscr{L}_{1}$ such that

$X_{n} \longrightarrow X$ almost everywhere and in the $\mathscr{L}_{1}$-norm.

Proof. Clearly, $\left\{X_{n}, \mathfrak{B}_{n}\right\}$ becomes fairer with time, so from Theorem 1 there exists $X \in \mathscr{L}_{1}$ with $X_{n} \stackrel{\mathscr{L}_{1}}{\longrightarrow} X$. Now, for an arbitrary subsequence $\left\{n^{\prime}\right\}$,

$$
\left|X_{m}-X\right| \leqq\left|X_{m}-E\left(X_{n^{\prime}} \mid \mathfrak{B}_{m}\right)\right|+\left|E\left(X_{n^{\prime}}-X \mid \mathfrak{B}_{m}\right)\right|+\left|E\left(X \mid \mathfrak{B}_{m}\right)-X\right| \text {. }
$$

By Levy's theorem, the third term is less than $\varepsilon / 3$ for large enough $m$. The first term is also bounded by $\varepsilon / 3$ for large $m, n^{\prime}$ since $\left\{X_{n}, \mathfrak{B}_{n}\right\}$ is a martingale in the limit. We must now show that the second term is small. Note first that for an arbitrary $\sigma$-field $\mathscr{A}$ we have

$$
E\left(X_{n} \mid \mathscr{A}\right) \stackrel{\mathscr{L}_{1}}{\longrightarrow} E(X \mid \mathscr{A} \text {. }
$$

Now start with the $\sigma$-field $\mathfrak{B}_{1}$ and note that the convergence $E\left(X_{n} \mid \mathfrak{B}_{1}\right) \stackrel{\mathscr{L}_{1}}{\longrightarrow} E\left(X \mid \mathfrak{B}_{1}\right)$ implies the existence of subsequence $\left\{n_{1}\right\} \subset\{n\}$ with $E\left(X_{n_{1}} \mid \mathfrak{B}_{1}\right) \rightarrow E\left(X \mid \mathfrak{B}_{1}\right)$ almost everywhere. Continuing, we have $E\left(X_{n_{1}} \mid \mathfrak{F}_{2}\right) \stackrel{\mathscr{L}_{1}}{\longrightarrow} E\left(X \mid \mathfrak{F}_{2}\right)$, and we can extract $\left\{n_{2}\right\} \subset\left\{n_{1}\right\}$ with $E\left(X_{n_{2}} \mid \mathfrak{F}_{2}\right) \rightarrow$ $E\left(X \mid \mathfrak{B}_{2}\right)$ almost everywhere. Thus, there exists a subsequence $\{\bar{n}\} \subset$ $\{n\}$ with $E\left(X_{\bar{n}} \mid \mathfrak{B}_{m}\right) \rightarrow E\left(X \mid \mathfrak{B}_{m}\right)$ a.e. for all $m$, namely the diagonal subsequence. Now choose $\left\{n^{\prime}\right\}$ as a subsequence of $\{\bar{n}\}$, and we can bound the second term above by $\varepsilon / 3$.

Applications. 1. Let $\left\{y_{k}\right\}$ be a sequence of independent random variables such that

$$
\lim _{\substack{m \rightarrow \infty \\ n \rightarrow \infty}} \int\left|\sum_{m}^{n} y_{k}\right|=0
$$

Then $\sum_{1}^{\infty} y_{k}$ exists a.e. and in the $\mathscr{L}_{1}$-norm.

Proof. Set $S_{n}=\sum_{1}^{n} y_{k}$. Then

$$
\int_{A}\left|S_{n}\right| \leqq \int_{A}\left|S_{m}\right|+\int\left|\sum_{m+1}^{n} y_{k}\right|
$$


so it is clear that $\left\{S_{n}\right\}$ is uniformly integrable. Further, setting $\mathfrak{B}_{n}=\sigma\left(y_{1}, y_{2}, \cdots, y_{n}\right)$, we have

$$
\left|E\left(S_{n} \mid \mathfrak{B}_{m}\right)-S_{m}\right|=\left|\int \sum_{m+1}^{n} y_{k}\right| \leqq \int\left|\sum_{m+1}^{n} y_{k}\right|,
$$

so $\left\{S_{n}, \mathfrak{B}_{n}\right\}$ is a uniformly integrable martingale in the limit.

2. Let $\left\{X_{n}, \mathfrak{B}_{n}\right\}$ be an adapted uniformly integrable sequence with $\left|E\left(X_{n+1} \mid \mathfrak{B}_{n}\right)-X_{n}\right| \leqq c_{n}$ where $\left\{c_{n}\right\}$ is a sequence of constants with $\sum_{1}^{\infty} c_{n}<\infty$. Then there exists $x \in \mathscr{L}_{1}$ with $X_{n} \rightarrow X$ almost everywhere and in the $\mathscr{L}_{1}$-norm.

Proof. We have

$$
\begin{aligned}
E\left(X_{n} \mid \mathfrak{B}_{m}\right)-X_{m} & =\sum_{m}^{n-1} E\left(X_{k+1}-X_{k} \mid \mathfrak{B}_{m}\right) \\
& \left.=\sum_{m}^{n-1} E\left(E_{k+1}-X_{k} \mid \mathfrak{B}_{k}\right) \mid \mathfrak{B}_{m}\right) .
\end{aligned}
$$

Thus

$$
\left|E\left(X_{n} \mid \mathfrak{B}_{m}\right)-X_{m}\right| \leqq \sum_{m}^{n-1} c_{k}
$$

Editorial note. See also R. Subramanian, "On a generalization of Martingales due to Blake," Pacific J. Math., 48, No. 1, (1973), 275-278.

\section{REFERENCES}

1. L. Blake, $A$ note concerning a class of games which become fairer with time, to appear, Glasgow Math. J.

2. - A generalization of martingales and two consequent convergence theorems, Pacific J. Math., 35, No. 2, (1970).

3. J. Neveu, Mathematical Foundations of the Calculus of Probability, Holden-Day, (1965).

Received June 23, 1972 and in revised form October 2, 1972. This research was supported by a University of Maryland General Research Board Grant, Summer 1972.

UNIVERSITY OF MARYLAND 


\section{PACIFIC JOURNAL OF MATHEMATICS}

\section{EDITORS}

RICHARD ARENS (Managing Editor)

University of California

Los Angeles, California 90024

R. A. Beaumont

University of Washington

Seattle, Washington 98105
J. DUGUNDJI*

Department of Mathematics

University of Southern California

Los Angeles, California 90007

D. Gilbarg and J. Milgram

Stanford University

Stanford, California 94305

\section{ASSOCIATE EDITORS}
E. F. BECKENBACH
B. H. NeumanN
F. WOLF
K. YosHIDA

\section{SUPPORTING INSTITUTIONS}

UNIVERSITY OF BRITISH COLUMBIA
CALIFORNIA INSTITUTE OF TECHNOLOGY
UNIVERSITY OF CALIFORNIA
MONTANA STATE UNIVERSITY
UNIVERSITY OF NEVADA
NEW MEXICO STATE UNIVERSITY
OREGON STATE UNIVERSITY
UNIVERSITY OF OREGON
OSAKA UNIVERSITY

UNIVERSITY OF BRITISH COLUMBIA

UNIVERSITY OF CALIFORNIA

MONTANA STATE UNIVERSITY

UNIVERSITY OF NEVADA

OREGON STATE UNIVERSITY

OSAKA UNIVERSITY
UNIVERSITY OF SOUTHERN CALIFORNIA

STANFORD UNIVERSITY

UNIVERSITY OF TOKYO

UNIVERSITY OF UTAH

WASHINGTON STATE UNIVERSITY

UNIVERSITY OF WASHINGTON

\section{AMERICAN MATHEMATICAL SOCIETY} NAVAL WEAPONS CENTER

* C. R. DePrima California Institute of Technology, Pasadena, CA 91109, will replace J. Dugundji until August 1974. 


\section{Pacific Journal of Mathematics}

\section{Vol. 48, No. $1 \quad$ March, 1973}

Jan Aarts and David John Lutzer, Pseudo-completeness and the product of Baire

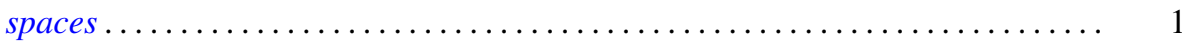

Gordon Owen Berg, Metric characterizations of Euclidean spaces ............ 11

Ajit Kaur Chilana, The space of bounded sequences with the mixed topology ..... . 29

Philip Throop Church and James Timourian, Differentiable open maps of

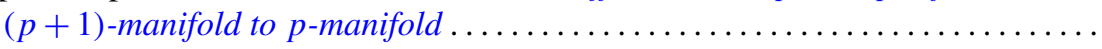

P. D. T. A. Elliott, On additive functions whose limiting distributions possess a finite

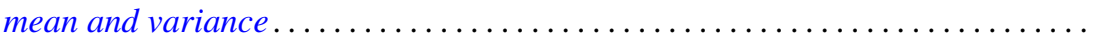

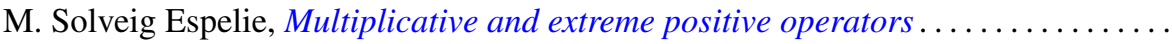

Jacques A. Ferland, Domains of negativity and application to generalized convexity

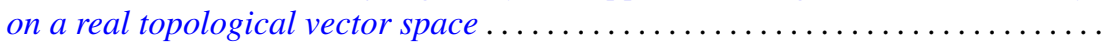

Michael Benton Freeman and Reese Harvey, A compact set that is locally holomorphically convex but not holomorphically convex ...............

Roe William Goodman, Positive-definite distributions and intertwining

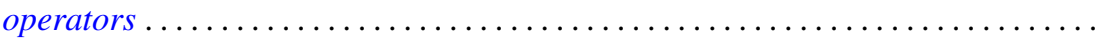

Elliot Charles Gootman, The type of some $C^{*}$ and $W^{*}$-algebras associated with

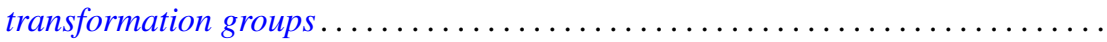

David Charles Haddad, Angular limits of locally finitely valent holomorphic

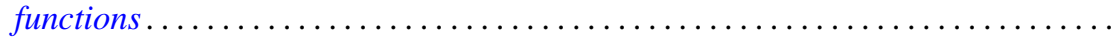

William Buhmann Johnson, On quasi-complements .

William M. Kantor, On 2-transitive collineation groups of finite projective spaces...

Joachim Lambek and Gerhard O. Michler, Completions and classical localizations of right Noetherian rings

Kenneth Lamar Lange, Borel sets of probability measures ......

David Lowell Lovelady, Product integrals for an ordinary differential equation in a Banach space

Jorge Martinez, A hom-functor for lattice-ordered groups .........

W. K. Mason, Weakly almost periodic homeomorphisms of the two sphere ....

Anthony G. Mucci, Limits for martingale-like sequences .......

Eugene Michael Norris, Relationally induced semigroups ...

Arthur E. Olson, A comparison of c-density and $k$-density ......

Donald Steven Passman, On the semisimplicity of group rings of linear groups.

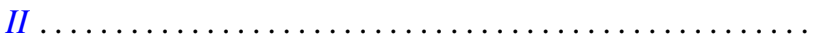

Charles Radin, Ergodicity in von Neumann algebras .

P. Rosenthal, On the singularities of the function generated by the Bergman operator of the second kind.

Arthur Argyle Sagle and J. R. Schumi, Multiplications on homogeneous spaces,

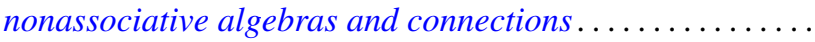

Leo Sario and Cecilia Wang, Existence of Dirichlet finite biharmonic functions on

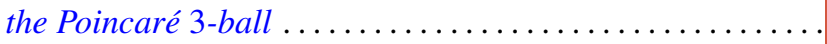

Ramachandran Subramanian, On a generalization of martingales due to Blake ..

Bui An Ton, On strongly nonlinear elliptic variational inequalities.

Seth Warner, A topological characterization of complete, discretely valued

fields. 